\title{
Hodgkin's disease with pulmonary cavitation
}

\author{
MICHAEL L. FRIEDLAND* \\ M.D.
}

\author{
EDWARD G. WITTELS \\ M.D.
}

\author{
ALLAN DEUTSCH \\ M.D.
}

The Section of Medicine, Brown University, and the Division of Hematology-Oncology, Department of Medicine, The Miriam Hospital, Providence, Rhode Island, USA

\begin{abstract}
Summary
A case of Hodgkin's disease presenting with pulmonary cavitation is reported. The relevant literature is reviewed.

\section{Introduction}

Pulmonary involvement with Hodgkin's disease has been estimated to occur in $40 \%$ of most large series (Ellman and Bowdler, 1960; Sternberg, Sidransky and Ochsner, 1959). Primary pulmonary Hodgkin's disease is most uncommon, and in Kern's review of the literature only 18 cases were noted to fulfill the criteria that were established by the authors (Kern, Crepeau and Jones, 1961). Since that time three additional case reports of Hodgkin's disease with cavitary pulmonary lesions have been published, one of which was not a primary presentation (Steel, 1964; Dhingra and Flance, 1970; Korbitz, 1970).

We report on a patient presenting with multiple pulmonary cavities as the primary site of involvement with Hodgkin's disease.
\end{abstract}

\section{Case report}

A 68-year-old white woman was found to have an abnormal chest $\mathrm{X}$-ray before admission for an elective orthopaedic procedure in February, 1981. A chest X-ray in June 1980 had been interpreted as unremarkable.

Pertinent physical findings included a temperature of $38.7^{\circ} \mathrm{C}$ and fullness below the left clavicle. No other lymphadenopathy or organomegaly was found. The chest X-ray (Fig. 1) showed bilateral pulmonary cavitating lesions. The white cell count was $19 \times 10^{9} /$ litre with a normal differential.

\footnotetext{
*Present address: New York Medical College, Department of Medicine, Munger Pavilion, Valhalla, New York 10595, U.S.A.
}

Bronchoscopy was performed and specimens were obtained for culture and cytology. Cultures for fungi, acid-fast and pyogenic bacteria were negative. Specimens obtained for cytologic examination demonstrated large cells consistent with malignancy suggestive of lymphoma. Further non-invasive studies including a liver and spleen scan and abdominal ultrasound were within normal limits. A bone marrow aspirate and biopsy were performed which were interpreted as within normal limits. A scalene node biopsy on the left demonstrated nodular sclerosistype Hodgkin's disease.

Because of the multiple pulmonary lesions, a history of fever, night sweats and weight loss, it was elected to treat the patient with combination chemotherapy consisting of nitrogen mustard, vincristine, procarbazine and prednisone given on the first and fourth cycles.

The patient's fever promptly subsided after the first cycle of chemotherapy and a repeat chest X-ray obtained one month later was normal (Fig. 2).

\section{Discussion}

The diagnosis of Hodgkin's disease as the cause for the cavitary lesions in our patient could not be made with certainty from the chest $\mathrm{X}$-ray alone. The abnormal cytology noted from specimens obtained at bronchoscopy, and the negative cultures for infectious agents lent support to a diagnosis of malignancy which was confirmed by the scalene node biopsy. Further confirmation was obtained indirectly by the improvement in the clinical and radiographic findings following combination chemotherapy.

Cavity formation in pulmonary Hodgkin's disease has been estimated to occur in less than $1 \%$ of all patients (Korbitz, 1970; Meese et al., 1964). Primary pulmonary Hodgkin's disease presenting as a cavitary lung lesion is extremely uncommon, with three cases reported by Kern et al. (1961) and one by Meese 


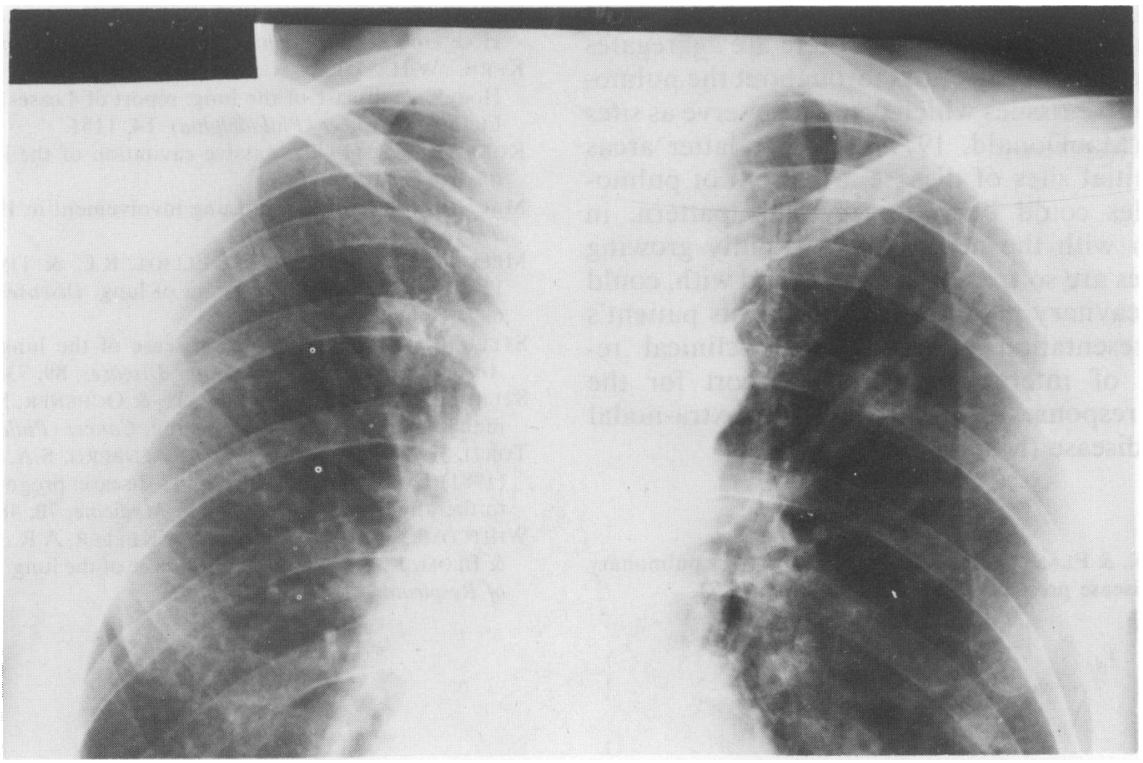

FIG. 1. Admission chest film-pre-treatment.

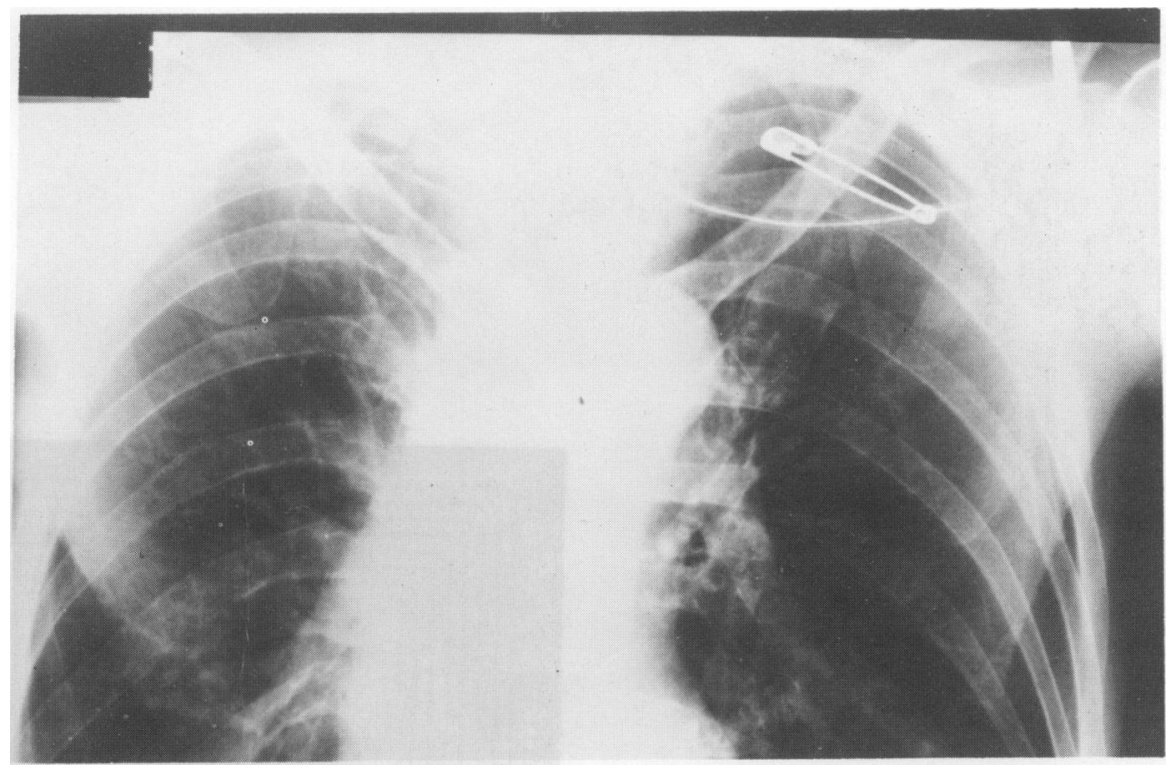

FIG. 2. Post-treatment chest film.

et al. (1964). Of additional interest is the observation by Whitcomb et al. (1972) of the frequency with which nodular sclerosing Hodgkin's disease produces pulmonary involvement. Fifty to $90 \%$ of the patients with nodular sclerosis in this series developed lung lesions, whereas only 5 to $20 \%$ of other histological types produced pulmonary lesions. Our patient had nodular sclerosis type Hodgkin's disease which is consistent with Whitcomb's observations.

The major sites of organized pulmonary lymphoid 
tissue include the areas of bifurcation of the major bronchi and vessels. In addition, there are aggregates of lymphoid tissue distributed throughout the pulmonary connective tissues which could also serve as sites of disease (MacDonald, 1977). If these latter areas were the initial sites of disease, a pattern of pulmonary nodules could be observed. This pattern, in conjunction with the necrosis that rapidly growing malignancies are so frequently associated with, could result in a cavitary pattern of disease. This patient's unusual presentation and favourable clinical response are of interest and lend support for the improving response to therapy seen in extra-nodal Hodgkin's disease (MacDonald, 1977).

\section{References}

DHINGRA, M.K. \& FlANCE, I.J. (1970) Cavitary primary pulmonary Hodgkin's disease presenting as pruritus. Chest, 58, 71.
Ellman, P. \& Bowdler, A.J. (1960) Pulmonary manifestations of Hodgkin's disease. British Journal of Diseases of the Chest, 54, 59.๕

KerN, W.H., Crepeau, A.G. \& Jones, J.C. (1961) PrimaryC Hodgkin's disease of the lung: report of 4 cases and review of the literature. Cancer (Philadelphia), 14, 1151.

KORBITZ, B.C. (1970) Massive cavitation of the lung in Hodgkin's disease. Chest, 58, 542.

MACDONALD, J.B. (1977) Lung involvement in Hodgkin's disease. $\frac{\bar{\sigma}}{\bar{\omega}}$ Thorax, 32, 664

MeEse, E.H., Doohen, D.J., Elliot, R.C. \& Timmes, J.J. (1964) Primary malignant lymphoma of lung. Diseases of the Chest, 46, 699.

STEEL, S.J. (1964) Hodgkin's disease of the lung with cavitation.American Review of Respiratory Diseases, 89, 736.

STERnberG, W.H., Sidransky, H. \& OChSNer, S. (1959) Primary $\vec{二}$ malignant lymphomas of the lung. Cancer (Philadelphia), 12, 806. W

TORTI, F.M., Portlock, C.S., Rosenberg, S.A. \& KaPlan, H.S (1981) Extralymphatic Hodgkin's disease: prognosis and responsec to therapy. American Journal of Medicine, 70, 487.

WhITCOMB, M.D., SCHWARZ, M.I., KELLER, A.R, FLANNERY, E.P. \& BLOM, J. (1972) Hodgkin's disease of the lung. American Review. of Respiratory Diseases, 106, 79. 